\title{
Egge Simon Mulder, hoogleraar
}

\author{
1956-1970 \\ A P B Breytenbach \\ Universiteit van Pretoria
}

\begin{abstract}
Egge Simon Mulder, professor from 1956 to 1970

E S Mulder succeeded Berend Gemser as professor in Old Testament Studies in the Faculty of Theology (Sec A) at the University of Pretoria. His approach was historicalcritical and at the same time he was totally committed to the ecclesiastical ministry. He can be characterised as an exponent of so-called Ethical Theology. Although he did not fully integrate his scientific work and his theologising within the scope of the church, he contributed to the present close ties between the Faculty and the Nederduitsch Hervormde Church, as well as to the ethos that there is no dichotomy between reason and faith.
\end{abstract}

Egge Simon Mulder het Berend Gemser in 1956 opgevolg as hoogleraar in die Departement Ou-Testamentiese Wetenskap aan die Fakulteit Teologie (Afd A). Hy was die eerste Suid-Afrikaans gebore Ou-Testamentikus van die Nederduitsch Hervormde Kerk. Hy was trouens die eerste uit die geledere van die Nederduitsch Hervormde Kerk wat gepromoveer het in die Ou-Testamentiese Wetenskap.

Egge Mulder is op 13 Augustus 1905 gebore op die plaas Sukkelaar in die Bethaldistrik. Hy was die derde kind van Cornelis Egges Mulder en Elsabe van Rheede van Oudtshoorn. C E Mulder was hoof van die plaasskool op Sukkelaar. Hy het as jong Nederlandse onderwyser na Suid-Afrika geömmigreer. 
Ná sy skoolopleiding aan die laerskool op Sukkelaar en die hoërskool Hoogenhout op Bethal, skryf Egge Mulder in vir BA met die oog op BD aan die Transvaalse Universiteitskollege. Sy leermeesters was onder andere J H J A Greyvenstein, S P Engelbrecht en B Gemser, van wie laasgenoemde ongetwyfeld die sterkste akademiese invloed op die jong Mulder uitgeoefen het (Mulder 1954a:III). Na suksesvolle voltooiing van sy studies word hy op $30 \mathrm{Mei} 1930$ georden as predikant van die Nederduitsch Hervormde Gemeente Zwartruggens. Hy tree op 13 Mei 1931 in die huwelik met Elizabeth Jacomina Schutte. Hy bedien agtereenvolgens die gemeentes Bronkhorstspruit (1931), Springs (1944), Pretoria (1949) en Pretoria-Oos (1952). In 1956 word hy aangestel as hoogleraar in Ou-Testamentiese Wetenskap. Hy is dekaan van die Fakulteit Teologie (Afd A) vanaf 1960 tot 1969. Hy emeriteer in 1970 en is op 11 Mei 1974 oorlede (Almanak 1991:139).

E S Mulder se akademiese loopbaan het reeds in 1929 begin toe hy van tyd tot tyd deeltyds dosent was in Semitiese Tale aan die Transvaalse Universiteitskollege (later die Universiteit van Pretoria). Hy vertrek op 24 Julie 1938 na die Rijksuniversiteit te Utrecht in Nederland vir doktorale studie in die Ou Testament onder leiding van Johannes de Groot (Die Hervormer 1940:17). De Groot was goed onderlê in die Semitiese Tale. Hy het onder andere Hebreeuse taal- en letterkunde, Oudheidkunde en Arabies gedoseer (Mulder 1943:42). Mulder lê aan die einde van 1939 sy doktorale eksamen af by De Groot en Obbink (Mulder 1943:42; 1954a:III). Die uitbreek van die Tweede Wêreldoorlog het hom egter verhinder om aan sy proefskrif te begin werk en hy keer onder moeilike omstandighede met sy gesin uit 'n oorloggeteisterde Europa terug na Suid-Afrika.

Eers in 1953 kry Mulder geleentheid om na Nederland terug te keer en sy studies te hervat. Aangesien De Groot intussen oorlede is, doen hy sy proefskrif onder die promotorskap van die Groningse Ou-Testamentikus Th C Vriezen. Sy proefskrif handel oor Jesaja 24-27 en is getitel 'Die teologie van die Jesaja-apokalipse'. Tydens die verdediging van sy proefskrif maak Mulder onder andere die volgende stellings (Mulder 1954b):

I. Die voorstelling dat die جִִּ onsterflik is vind in die Ou Testament geen steun nie.

II. Die woorde van Jonathan in 1 Sam 14:43 הִנִ י op te neem.

III. Die omskrywing van die grens $n$ $34: 11$ ) is in die Afrikaanse Bybelvertaling, 'skrams oor die hange van die meer Kinneret' 'n juister weergawe as dié van die NBG. met 'langs den oever van de zee Kinnereth'. 
IV. Die eksegese van Van Gelderen van 2 Kon 3:27 dat die toorn wat oor Israel gekom het die toorn van Jahwe is i.p.v. die toorn van Kamos, moet afgewys word. (Korte Verklaring, De Boeken der Koningen, Tweede Deel, Kampen, 1936, p.396 vv.).

V. Die stelling van S. du Toit, (in Bybelse en Babilonies-Assiriese Spreuke, Johannesburg, 1942, p. 79) dat in die Ou Testament is die wysheid dus suiwer religieus-eties van aard', is 'n eensydige beklemtoning van die Israelitiese wysheidsbegrip.

VI. Die woorde van Jesus in Markus 3:3, é yepe els tò $\mu$ éoov, is in die Afrikaanse Bybelvertaling beter weer te gee met 'Kom staan in die middel' as met 'Staan op tussen hulle in'.

IX. Die wyse waarop Prof. Dr S.P. Engelbrecht die ontstaan van die Nederduits Gereformeerde Kerk in Transvaal in 1866 teken (in Geskiedenis van die Nederduitsch Hervormde Kerk van Afrika, Kaapstad-Pretoria, 1953, p 191 vv. en in Hervormde Teologiese Studies, Pretoria, Augustus 1953, p. 181 w.) word bevestig deur die historiese feite. (contra Stelling $X$ in J.A. Heyns, Die Grondstruktuur van die Modalistiese Triniteitsbeskouing, Kampen, 1953).

XI. Die snelle uitbreiding van die Nederduitsch Hervormde Kerk van Afrika maak die vermindering van die ledetal van die Algemene Kerkvergadering (Generale Synode) noodsaaklik. (Die Algemene Kerkvergadering is saamgestel uit alle diensdoende predikante van die Kerk, hoogstens twee afgevaardigdes uit elke gemeente en die teologiese professore van die Kerk).

XII. Die indeling van die stadsgemeentes van die Nederlandse Hervormde Kerk in wyke (na 1951 in wykgemeentes) dien mettertyd opgevolg te word deur die vorming van kleinere geheelselfstandige gemeentes om so die geestelike bearbeiding meer doeltreffend te maak en tot aktivering van alle gemeentelede te kom.

Uit hierdie stellings word dit duidelik dat Mulder veral geïnteresseerd was in die eksegese van die Ou Testament, dat hy in aansluiting daarby ' $n$ besondere belangstelling in Bybelvertaling getoon het, dat hy hom tuis gevoel het binne die gedagteklimaat van die Nederduitsch Hervormde Kerk en dat die kerkordelike bestuur van die kerk hom na aan die hart gelê het. Hier skemer ook reeds deur dat Mulder eerder 'n toegewyde kerkman as akademikus was. 
Mulder se proefskrif getuig van deeglike navorsing en 'n hoë akademiese standaard. Dit is goed ontvang in akademiese kringe en kan sonder twyfel beskou word as 'n goeie wetenskaplike bydrae tot die studie van die Jesajaboek. Soos te verwagte, was Mulder se navorsingswerk wat in die proefskrif neerslag gevind het, in 'n baie hoë mate histories-krities van aard. By 'n bestudering van die proefskrif is dit gou duidelik dat sy kennismaking met geleerdes soos De Liagre Böhl en sy bywoning van lesings in Babilonies-Assiries en Godsdiensgeskiedenis sy visie op die teks en leefwêreld van die Ou Testament geweldig verbreed het. Metodies is daar in die proefskrif sterk ooreenkoms met Europese en veral Duitse kommentare van dié tyd. Op tekskritiese terrein gebruik Mulder byvoorbeeld alle tersaaklike materiaal soos die gegewens wat by Qumran aan die lig gekom het. Hy openbaar egter 'n gesonde respek vir die Masoretiese tekstradisie en maak hom nie skuldig aan die Konjekturfreudigkeit wat dikwels in histories-kritiese kringe die botoon gevoer het nie. In sy uitleg toon Mulder dat hy die klassieke Hebreeus ten volle bemeester het en dat hy ander Semitiese tale en Grieks ook met gemak beheer. Hy aanvaar etimologie en vergelykende taalkunde as legitieme verklaringswyses, maar het tog ook 'n oop oog vir die verskillende betekenismoontlikhede van woorde en woordkombinasies in verskillende kontekste (vgl Mulder 1954a:7, 18, 19, 94 vn 2). Die konklusies waartoe hy kom, word begrond met deeglike wetenskaplike eksegese (Mulder 1954a:67121). Hy is nugter en oorwoë in sy oordeel en formuleer sy resultate in keurige Afrikaans. Die vertaling van Jesaja 24-27 wat Mulder bied, verraai egter talle Hebraïsmes soos die vooropstelling van die werkwoord (vgl bv Mulder 1954a:8).

Uit 'n vergelyking van die werk wat Mulder voor sy doktorale studie gelewer het en die werk in sy proefskrif en daarna, is dit duidelik dat hy geweldig gebaat het by die oorsese studie en blootstelling aan die Europese akademiese wêreld. So maak hy byvoorbeeld in 1934 die volgende stelling oor die godsdienstige situasie in Israel ná die val van Samaria: 'Maar nou deur die invoering van die vreemde koloniste het vreemde gebruike ook ingesluip, maar tog het die Jehova-godsdiens [sic] die oorhand bly behou' (Almanak 1934:108). Hy sê byvoorbeeld ook van die Samaritaanse Pentateug die volgende: 'Hulle het ook die vyf boeke van Moses, wat toe as versamelde boeke voorhande was, besit. Ter wille van die volk is die Hebreeuse boek in die Samaritaanse skrif opgestel en later ook in die Samaritaanse taal vertaal' (Almanak 1934:109). Ná sy studie soek 'n mens verniet na soortgelyke stellings in sy werk.

Sy studie in Nederland het by hom ook 'n vernuwing van gees gebring. Dit het ongetwyfeld 'n bydrae gelewer tot sy positiewe ingesteldheid teenoor die sending in 'n tyd toe baie kollegas en ampsdraers van die Nederduitsch Hervormde Kerk nog negatief gestaan het teenoor sending onder die swart volke in Suid-Afrika. Sy 
bewustheid van die besondere probleem waarvoor die sending onder die swart volke te staan gekom het, kom onder andere tot uitdrukking in stelling $X$ van die verdediging van sy proefskrif wanneer hy sê: 'In die studiekursus Fenomenologie van die Godsdiens aan die Fakulteit van Godgeleerdheid aan die Universiteit van Pretoria dien ruimer geleentheid gebied te word vir die bestudering van die verskynsele van die godsdienste van die inheemse naturellebevolking van Suid-Afrika' (Mulder 1954b). In sy prediking is Mulder meermale 'n vurige pleitbesorger vir die sending. So verwys hy in 'n preek gehou te Pretoria op 24 Januarie 1950 na Jesaja 19:16 en sê hy van hierdie profetewoord:

Dit is, Broeders en Susters, die begin van die Sending. Reeds 550 jaar voor die koms van Christus het dit begin. En van daardie tyd af weet die gemeente van God dat daar nie soiets as 'n privaat, opgeslote Christendom is nie, nie 'n nasionale Christendom of Boerechristendom nie, maar dat die kerk die evangelie moet uitdra aan die volkere van die aarde, die nasies van die wêreld.

(Mulder 1951:30)

Hieruit blyk terloops ook dat, alhoewel hy onbeskaamd Afrikaner en Boer was, hy tog krities gestaan het teenoor afsondering en die uitlewering van die kerk en geloof aan nasionale emosies en voorkeure. In dieselfde preek maak hy die volgende uiters aanvegbare stellings in verband met die sendingmotief:

In die teenwoordige tyd en in die teenwoordige wêreld het ons wel dubbele rede om die blye boodskap uit te dra. Sien ons nie elke dag wat die goddeloosheid in die wêreld uitrig nie? Reeds ter wille van onsself, 'n uiters selfsugtige rede, moet ons dit doen. Wat sal van ons word as die magte wat reeds tussen ons werksaam is hulle ongesteurd kan ontplooi? Wat sal word as die magte van die Ooste, die gekleurde nasies, hulle teen ons keer? Wat is ons toekoms wanneer die gekleurdes in ons midde, die hand teen ons sou ophef? Hulle bepaal saam die lot van die volkerewêreld, ook ons eie lot, soos blyk in die afgelope maand. Ons moet wens dat China, Indië, Rusland, die Swart rasse in ons midde en op ons vasteland, so gou as moontlik van die gees van die evangelie deurdring word. Dit is die enigste heil wat ek vir ons volk sien.

(Mulder 1951:32-33)

Die ander rede wat Mulder in dieselfde preek aanvoer vir die noodsaaklikheid van sending, is wel Bybels verantwoord. Hy stel dit so: 
Maar as gemeente van Christus, moet die liefde van Christus ons ook dring om ander deelgenoot te maak van ons groot blydskap...Ons is die boodskap van heil aan hulle verskuldig. Die Heer self het ons die opdrag gegee. Ons doen sonde teen die Evangelie en teen hulle, as ons sou versuim. Ons het geen reg om dit in selfsug aan eie bors vas te druk en te sê: 'Dit is net ons s'n.'

(Mulder 1951:33)

In sy bekendstelling van die nuwe kerkwet in 1952 kom dieselfde simpatieke ingesteldheid en ywer vir die sending na vore as hy sê:

Die kerk moet getuie wees, getuig teenoor die volk Israel, teenoor die heidene en teenoor die wat vervreemd het van die kerk. Ons Kerk het in die tyd wat agterlê hierdie opdrag van die Heer verwaarloos. Ons moet met skaamte ons skuld bely voor God. Hierdie opdrag het ons oorgelaat aan ander, aan die mense wat daarvoor gevoel het en daarin belanggestel het, aan 'n sukkelende genootskap uit lede van ons kerk. Met die aanvaarding van die nuwe Kerkwet wil die Kerk die opdrag vervul, in gehoorsaamheid aan Christus. Die Kerk wil Christus bely en van Christus getuig in die wêreld.

(Almanak 1952:136)

Die akademiese potensiaal wat Mulder openbaar het in sy proefskrif, het egter nooit tot volle ontplooiing gekom nie. Dit word byvoorbeeld duidelik wanneer die min publikasies wat hy gelewer het, in berekening gebring word. Behalwe sy proefskrif wat gepubliseer is, het hy slegs nege artikels in Hervormde Teologiese Studies gepubliseer, waarvan twee preke was, een ' $n$ rede uitgespreek by die opening van die Fakulteit Teologie en een langer en een baie kort huldigingsartikel. Daarbenewens het hy 'n stuk of twintig populêr-wetenskaplike artikels en oordenkings gepubliseer in Die Hervormer en Almanak en het hy een boek vertaal vir die proefvertaling wat in 1970 gepubliseer is.

Die rede waarom Mulder se akademiese potensiaal nooit werklik ontplooi het nie, moet waarskynlik gesoek word by die feit dat hy in die eerste plek 'n gelowige kerkmens was en eintlik niks anders wou wees nie. Daarby moet in gedagte gehou word dat die soort histories-kritiese benadering wat in sy tyd aan die orde van die dag was by die studie van die Ou Testament in vele opsigte wesensvreemd was binne die konteks van ' $n$ entoesiastiese en warme meelewing met die kerk. Mulder was wel deeglik bewus van die probleem en hy kies doelbewus vir die koppeling van 'n kritiese wetenskaplike benadering en 'n sterk verbondenheid met die kerk waarin daar gesoek word na die boodskap van die Ou Testament as oorkonde van die 
openbaring van God. By die opening van die Fakulteit op 13 Februarie 1967 laat hy hom soos volg hieroor uit (Mulder 1967:7-9):

Daar het ' $n$ teologiese nieubesinning in die O.T. wetenskap ingetree sodat Joh. Hempel in 1927 skrywe - die histories-kritiese arbeid in al sy vertakkinge vorm nie 'n teenstelling met die teologiese opvatting van die O.T. as oorkonde van die openbaring nie;...Die reformatoriese besinning na die eerste wêreldoorlog het daartoe gelei dat juis die eksegese opnuut beklemtoon is en opnuut is die vraag gestel nl. hoe moet die histories kritiese eksegese met die hermeneutiese riglyn van die reformatoriese Bybeluitleg verbind word. Dit is 'n heersende probleem in die O.T. wetenskap van die huidige tyd. Twee dinge het in elke geval duidelik geword:

1. Die histories-kritiese navorsing het nie konsekwent na die boodskap van die Bybelteks gevra nie maar het hom dikwels laat lei deur ' $n$ rasionalistiese gedagtegang.

2. Dat dit onmoontlik is om reformatoriese Skrifuitleg te beoefen met verbygaan van die historiese kritiek.

Hy stel dan verder dat ook die uitleg van die Ou Testament slegs sy doel bereik wanneer die uitleg 'in Christus' geskied. Op voetspoor van Martin Noth verduidelik hy verder dat in die eksegese daar reg moet geskied aan die gegewe dat die Nuwe Testament Jesus Christus as die doel van die Ou-Testamentiese Godshandeling verkondig (Mulder 1967:9). In sy slotwoord verwys hy weer na die noodsaaklikheid van wetenskap èn geloof as hy sê:

Ons kerk het altyd sy voorkeur uitgespreek vir universitêre opleiding bo die van ' $n$ kweekskool. Die kerk het dit so gesien dat sy bedienaars van die Woord universitêr-wetenskaplik geskoold moet wees. Dit is nie al nie. By die wetenskaplike vorming moet ons onthou dat ons ook dienare van die Woord binne die kerk is. Die kerk het verder bepaal dat die dosente aan die Fakulteit die hoogste akademiese kwalifikasies moet hê. Dit is nie al nie, hulle moet ook dienare van die Woord wees. Hulle is kragtens hulle aanstelling werknemers van die Universiteit, maar vooraf is hulle deur die kerk toegelaat tot die Evangeliebediening en dit open eers die weg om hoogleraar te kan word en so is dit die beste.

(Mulder 1967:10)

Mulder het sterk standpunt ingeneem teen 'n belydeniskerk en hom uitgespreek vir 'n belydende kerk. Hy stel dit so: 'Die kerk bely...maar bely word hier gesien as 'n 
aktiewe daad, 'n handeling van die kerk ook nou en hier. Waar bepaalde belydenisskrifte as absolute norms en maatstawwe gehanteer word, daar loop dit gewis en seker uit op ketterjag' (Almanak 1952:134).

In die lig van die voorafgaande sou Mulder as 'n verteenwoordiger van die Etiese Teologie getipeer kon word (vgl Loader 1987:48). Dit is volkome begryplik as in ag geneem word dat hy 'n leerling was van Gemser en ook sterk beïnvloed is deur etici soos H Th Obbink en F M Th de Liagre Böhl (Mulder 1954b:III). Hy het egter nie daarin geslaag om sy wetenskaplike arbeid en sy teologiebeoefening ten dienste van gelowiges in die kerk, ten volle te integreer nie. By sy studente het hy (in later jare altans) dikwels die indruk gelaat van 'n tweeslagtigheid in sy teologiebeoefening: Aan die een kant was sy eksegeselesings histories-krities en wetenskaplik van goeie gehalte, maar die relevansie daarvan vir die prediking en kerklike bediening het by die onervare studente verbygegaan. Aan die ander kant kon hy die swak en soms foutiewe eksegese van 'n student se klaspreek oor die hoof sien as die preek 'n deurleefde en warme getuienis van geloof was.

Hierdie tweeslagtigheid kom inderdaad ook na vore in Mulder se kerkwerk. Dat hy 'n geliefde prediker was, staan vas. Sy siening oor wat prediking is, kom duidelik na vore in die volgende stellings: 'Wie die verhaal van die priesterskrywer in Gen 1:1-2:4a lees en rustig op hom laat inwerk kom onder die indruk van die verhewe eenvoud, maar ook die verwonderende aanbidding; hierdie hoofstuk is dan ook prediking in sy suiwerste en skoonste vorm' (Mulder 1959:112). Mulder sien dus die prediking as 'n gebeure waarin die gelowige in sy ontmoeting met die lewende God deur die woord oorweldig word. In 'n intreepreek gehou op 27 Maart 1949 laat hy hom soos volg daaroor uit:

Voor ons die nuwe gemeente, maar voor ons ook die ou Bybel, en bo ons dieselfde oop hemel, dieselfde troue God en Vader, en by ons en in ons dieselfde liefdevolle en vriendelike Heiland wat gister en vandag en in ewigheid dieselfde bly. Hy bestuur die weë en gange van elkeen van ons. Hy is die groot opdraggewer en sender. Hy spreek en ons moet luister. Daarom hoor u ook nie vanmôre 'n ontvouing van 'n werkprogram, of van die voornemens en planne vir die toekoms nie daaroor lag Hy wat in die hemel woon. Nee, ons kom saam om te luister na Hom wat hier in ons midde staan. Hy wat die hart van die gemeente is, die hart van die Evangelie, die hart van die Vader, na Jesus Christus wat mag het om sy woord waar en werklik te maak, daar by die See van Galilea, tweeduisend jaar gelede, netsowel hier in Pretoria, nou, vandag, môre en in die toekoms. Ons kom om te luister na sy woord, in gehoorsaamheid aan daardie woord. En die woord 
keer nie leeg na hom terug nie, maar doen wat Hom behaag en is voorspoedig in alles waartoe $\mathrm{Hy}$ dit stuur.

(Mulder 1949:1)

As deel van sy oorredende styl en téen sy vorming as akademikus in, huiwer Mulder nie om die vertelling in Lukas 5:1-11 uit te bou en allegories toe te pas op die gemeente en sy werk in die gemeente nie. Hy sê byvoorbeeld:

Baan na baan en strook na strook het die uitgespreide net die vis aangejaag, met reëlmatigheid en orde is dit gedoen. So is die uitgestrektheid deursoek. Netso kan ons die Evangelie nie oral tegelyk bring nie. Ons moet die net trek deur elke waterstrook om daaruit voort te bring wat daarin roer en leef en beweeg. Dit is baiemaal verleidelik om die plek uit te soek waar ons meen dat volop vis is, waar die opbrengs en resultate gou tevrede stel. Vir die voorganger van die gemeente is dit gevaarlik...Dit is die manier om ons werk te doen, dan word niemand oorgeslaan nie. Die net moet laat sak word en getrek word deur elke diepte, waarin menseharte klop, elke diepte waar daar gevang kan word vir die koninkryk van die hemele...Die net mag vol wees, die kerk mag vol wees. Die skeiding is nie ons werk nie. Die net word skoongemaak, eenmaal, aan die strand van die ewigheid.

(Mulder 1949:4-5)

Dieselfde tweeslagtigheid kom na vore in sy siening van die verhouding tussen die Ou en die Nuwe Testament. Hy werk naamlik met belofte en vervulling as 'n hermeneutiese vertrekpunt omdat hy die Nuwe-Testamentiese interpretasie van die $\mathrm{Ou}$ Testament as deurslaggewend beskou. So verstaan hy byvoorbeeld die עִכִכ יהוה na na wie in Deutero-Jesaja verwys word, vanuit die Nuwe Testament, alhoewel hy bewus is van die probleme waarop só ' $\mathrm{n}$ verstaan in die Ou-Testamentiese teks stuit. Hy stel die saak soos volg:

Wie word bedoel met die Kneg van die Heere, waarvan hier sprake is. Partymaal lyk dit asof die volk Israel daarmee bedoel word, Israel, die geplaagde, die geslaande en die verdrukte volk; Israel sou dan die Godskneg onder die volke wees. Op ander plekke weer word duidelik verskil gemaak tussen die volk en die Kneg van die Heere. Mens sou kon dink die profeet bedoel homself, hy is die een wat deur God as 'my Kneg' aangespreek word. Maar ook hierdie opvatting stel nie tevrede nie. Ons moet liewer teruggaan na die beskouing van die eerste Christengemeente. Met die Kneg van die Heere word niemand anders bedoel as Jesus Christus, die Heer nie. En daarom is hierdie 
boek van die profeet 'n aankondiging van Jesus Christus. So sien Filippus dit ook en so verduidelik hy dit ook aan die kamerling van Ethiopië. Die profeet sien die dinge die toekoms in. Hoe, dit weet ons nie en dit verstaan ons nie. In die verre toekoms in, net so asof een van ons, nou in die jaar 1951 sien wat oor 550 jaar, dus in die jaar 2500 sal gebeur. Uit daardie verte sien hy die Godskneg, 'n man, 'n lydende, belaai met die skuld en die straf en die strieme van die mensheid om dit in hulle plek te dra. En van die Kneg sê hy: Hy is die lig van die volke, hy is die heil van die wêreld. Dit is iets groots en onbegryplik dat hierdie man te midde van duisterheid en ellende en verslawing en vertwyfeling, vyf en 'n halwe eeue vooruit die toekoms insie om so die lig van die wêreld en die heil van die nasies aan te kondig.

Die Ou Testament is 'n egte adventsboek. Dit handel oor die koms van God, die koms van sy ryk. Dit verkondig, nog eers in skaduwee en newels gehul, die een wat sal kom, die Messias, die Woord, wat kom na sy volke, om by hulle en met hulle te wees.

(Mulder 1951:30)

Dieselfde hermeneutiese vertrekpunt kom na vore wanneer Mulder sê: 'Tog beteken Sondag die vervulling van die beloftes, waarvan die sabbat die teken was. Maar net soos die ander beloftes van die Ou Testament word dit nie in 'n instelling verwerklik nie, ook nie in die Sondag nie, maar in die persoon van Jesus Christus, want in Hom is al die beloftes van God ja en amen' (Almanak 1970:27).

Uit bogenoemde aanhalings is dit duidelik dat Mulder nie die implikasies van sekere aspekte van sy wetenskaplike werk, veral op die terrein van die eksegese, ten volle deurdink en toegepas het nie. So byvoorbeeld sou hy in 'n eksegeselesing sterk daarop aandring dat die literêre verband waarin 'n woord of sin staan sowel as die leefwêreld van die Ou Testament bepalend is vir die betekenis van die woord of eenheid wat ter sprake is. Maar in 'n preek sou hy, byna op die wyse wat Childs later gepropageer het, die kanon as 'finale konteks' neem (vgl Childs 1979).

Mulder se bydrae tot die teologiese ontwikkeling in die Nederduitsch Hervormde Kerk gedurende die vyftiger- en sestigerjare moet nie onderskat word nie. Sy invloed het ver buite die grense van die Fakulteit gestrek. Sy onkreukbare karakter, sy opregtheid en die erns waarmee hy die Woord verkondig het, het by kerkmense vertroue gewek. Hierdie vertroue het reeds tot uitdrukking gekom toe hy nog predikant was. Hy is in 1937 en later weer in 1945 gekies as vise-skriba van die Kommissie van die Algemene Kerkvergadering. In albei gevalle is sy lidmaatskap van die Kommissie beëindig deur sy oorsese studie, te wete in 1938 en 1953 . Sy solidariteit met die kerk (al was dit ook soms 'n kritiese solidariteit) het die vertroue in hom 
versterk. Tydens die Geysersaak en al die onverkwiklikhede wat dit meegebring het, was dit veral die figuur van Mulder wat (sonder dat hy dit waarskynlik ooit bedink of bedoel het) die moontlike wantroue by kerklike ampsdraers in wetenskaplike eksegese getemper het. Mulder se integriteit het die potensiële trugolf téén 'n histories-kritiese benadering in die eksegese help stuit.

Gedurende en ná hierdie stormagtige tye kon Mulder ongestoord histories-krities werk en by sy studente aandring op verantwoordelike wetenskaplike eksegese. Tydens jy dekaanskap van die Fakulteit Teologie is die grondslag ook gelê vir hegte bande tussen kerk en Fakulteit. So het hy help bou aan dit wat vandag so vanselfsprekend is in die Nederduitsch Hervormde Kerk en waarop akademici van ander kerke jaloers is: dat die Nederduitsch Hervormde Kerk se akademici onbevange navorsing kan doen en die resultate kan bekendmaak en teologie krities kan bedryf sonder die vrees dat iemand oor hulle skouer loer.

'n Laaste nalatenskap van Mulder wat vermelding verdien is sy betrokkenheid by die vertaling van die Bybel. Hy het die voorstel gemaak wat so rigtinggewend vir die nuwe vertaling geword het, naamlik 'so getrou as moontlik aan die grondteks; 'n waardige vertaling wat ons volk aanspreek binne en buite die kerk, in die erediens en huislike gebruik, in ons teenswoordige situasie en tyd' (Almanak 1992:41). Ongelukkig is hy dit nie gegun om die nuwe vertaling te sien nie en kon hy voor sy siekte en dood slegs die boek Amos voorberei vir die proefvertaling van 1970.

Egge Simon Mulder se grootste bydrae was dat hy sy lewe lank ootmoedige gelowige kerkmens was.

\section{Literatuurverwysings}

Almanak 1934. Die Samaritane, 107-110.

--- 1952. Die nuwe kerkwet, 131-137.

--- 1970. Nuwemaan en sabbat, 24-27.

--- 1991. Vroeëre professore en dosente, 139.

--- 1992. Egge Simon Mulder: 13.8.1905-11.5.1973, 40-41.

Childs, B S 1979. Introduction to the Old Testament as Scripture. London: SCM.

Die Hervormer 1940. Reisherinneringe. Mei 1940, bl 17-19.

Loader, J A 1987. Tertium datur - oor die etiese waarheidsbegrip. HTS 43, 47-57.

Mulder, E S 1943. Personalia: Prof dr Joh de Groot. HTS 1, 42-43.

--- 1949. 'Op u woord sal ek die net laat sak'. HTS 6, 1-5.

--- 1951. Duisternis...en tog lig. HTS 8, 29-33.

--- 1954a. Die teologie van die Jesaja-apokalipse: Jesaja 24-27. Groningen: Wolters.

--- 1954b. Stellinge. (Bylae by 1954a.) 
Mulder, E S 1959. 'Die mens na die beeld van God' in die Ou Testament. HTS 15, 112-121.

... 1967. Enkele grepe uit die Ou-Testamentiese wetenskap in die afgelope vyftig jaar. HTS 22, 2-10. 